\title{
LA SUPRESIÓN DE LOS DEBATES DE POLÍTICA GENERAL DE LA CONSTITUCIÓN ESPAÑOLA DE 1978
}

\author{
Pedro Martínez Ruano \\ Profesor titular de derecho constitucional \\ Universidad de Almería (España) \\ E-mail: pmruano@ual.es
}

\begin{abstract}
RESUMEN: El presente estudio tiene por objeto analizar la supresión de los debates de política general del texto definitivo de la Constitución Española de 1978 por parte de la Comisión Mixta Congreso-Senado durante el proceso constituyente.

Palabras clave: proceso constituyente; debates de política general; derecho parlamentario; control parlamentario; funcion de impulso y dirección política; comisión mixta congreso-senado.
\end{abstract}

ABSTRACT: The present study aims to analyze the suppression of the general policy debates of the final text of the Spanish Constitution of 1978 by the Mixed Congress-Senate Commission during the constituent process.

Keywords: constituent process; general policy debates; parliamentary law; parliamentary control; political advocacy and direction function; congresssenate joint committee.

Sumario.- I. Introducción. II. Antecedentes. III. La Supresión De Los Debates De Política General De La Constitución Española De 1978. IV. La Tramitación En El Congreso De Los Diputados. V. La Tramitación en El Senado. VI. La Labor De La Comisión Mixta Congreso-Senado. VII. Conclusiones.

\section{INTRODUCCIÓN}

El presente estudio tiene por objeto analizar la supresión de los debates de política general del texto definitivo de la Constitución Española de 1978. A tal efecto estudiaremos el proceso de elaboración del texto constitucional a partir de la tramitación parlamentaria del mismo, sin profundizar en otros tipos de reflexión o examen.

Partiremos de la configuración de los debates de política general en el texto de Ponencia para, posteriormente, atender a su periplo por el Congreso de los Diputados y por el Senado, tanto ante las Comisiones respectivas como en los Plenos y, sobre todo, escrutando las enmiendas o votos particulares emitidos en relación a esta concreta temática. 
Finalizará el trabajo en el estudio de la labor de la Comisión Mixta congreso-Senado de cuyo texto final resultó de la definitiva supresión de los debates de política general en el texto constitucional.

\section{ANTECEDENTES}

La regulación de los debates de política general durante el proceso constituyente encuentra sus antecedentes en la Constitución de los Estados Unidos de América, que en su artículo II, $3^{\text {a }}$, señala que el Presidente informará periódicamente al Congreso sobre el estado de la Unión. Asimismo, la Constitución de Cádiz de 1812 reguló también dicho informe ${ }^{1}$, de forma análoga al State Opening británico y el subsiguiente "Queen's Speech debate". En Francia tiene sus antecedentes sobre todo durante los años 1860 a 1867, periodo en el que el Discurso del Trono, con el que se inauguraba la sesión y donde se exponía la política realizada, era utilizado por la Asamblea, que tenía la facultad de contestarlo, para ejercer su oposición política de forma análoga a como lo hacía en la votación de presupuestos.

A ello debe añadirse la práctica parlamentaria desarrollada durante la Legislatura Constituyente y la I Legislatura en donde fueron habituales las comunicaciones del Gobierno al Congreso sobre temas de gran relevancia.

\section{LA SUPRESIÓN DE LOS DEBATES DE POLÍTICA GENERAL DURANTE EL PROCESO CONSTITUYENTE}

La determinación de la naturaleza jurídica de los debates de política general y del debate sobre el estado de la Nación dentro de nuestro ordenamiento hace del análisis del proceso constituyente de 1978 un elemento esencial, en la medida en la que el Anteproyecto de Constitución en el título relativo a las Relaciones entre el Gobierno y las Cortes Generales recogía el carácter obligatorio de estos debates en cada periodo de sesiones.

El proceso constituyente ${ }^{2}$ se inició al activarse la iniciativa prevista en la Ley para la Reforma Política por parte del congreso de los Diputados el 26 de junio de 1977, constituyéndose una Comisión Constitucional encargada de elaborar un texto constitucional. En la sesión constitutiva de la misma, el 1 de agosto se creó una Ponencia que habría de redactar un Anteproyecto de Constitución. El 5 de enero de 1978 se publicó dicho Anteproyecto y los votos particulares emitidos en relación al mismo, encargándose la Comisión, ya llamada de Asuntos Constitucionales de debatir los mismos y las enmiendas presentadas durante 24 sesiones. El Dictamen de la Comisión, las enmiendas que se mantenían para su debate en el Pleno y los votos particulares se publicaron 111 de julio. Durante tres semanas el Pleno del Congreso debatió dicho votos particulares y enmiendas, publicándose el texto definitivo el 21 de julio.

1 Art. 123. El Rey hará un discurso, en el que propondrá a las Cortes lo que crea conveniente, y al que el Presidente contestará en términos generales. Si no asistiere el Rey, remitirá su discurso al Presidente para que por éste se lea en las Cortes

2 GUNTHER. R.: "El proceso constituyente español”, Revista de Estudios Políticos, Núm. 49. Enero-Febrero 1986, pp. 33-61. 
La tramitación parlamentaria en el Senado se inició el 26 de julio con la publicación del texto remitido por el Congreso y la apertura del plazo de presentación de enmiendas. Tras el debate en Comisión de la misma, el dictamen de ésta y los votos particulares se publicaron el 6 de octubre, mientras que el texto definitivo aprobado por el Pleno se publicó el 13 de octubre.

Ante la discrepancia entre el texto aprobado por el congreso y por el Senado se constituyó la Comisión Mixta, que redactó el texto definitivo, publicado el 28 de octubre y aprobado por los plenos del Congreso y del Senado el día 31 de dicho mes. El texto aprobado por las Cámaras se aprobaría en referéndum el 6 de diciembre y se publicaría en el Boletín Oficial del Estado el día 29 de diciembre de 1978.

Así las cosas, la desaparición de estos debates del definitivo texto constitucional es uno de los pequeños misterios de nuestra reciente historia jurídico-política. La singularidad de este fenómeno se debe al hecho de que la previsión de esta institución no fue objeto de ningún voto particular concreto, se recogió tanto en el texto final aprobado por el Congreso de los Diputados, como en el aprobado por el Senado y desapareció del texto final de la Constitución durante los trabajos de la Comisión Mixta Congreso-Senado, de cuyas sesiones, que tenían carácter secreto ${ }^{3}$, no hay actas publicadas oficialmente.

Esta cuestión pone de manifiesto la naturaleza constitucional del objeto del presente estudio, como elemento material del proceso constituyente y como instrumento básico de la articulación de las relaciones entre el Gobierno y las Cortes Generales, atendiendo a la ubicación sistemática del mismo en el Anteproyecto de Constitución, durante el proceso constituyente.

Así, el Anteproyecto de Constitución Española que reflejaba el texto elaborado por la Ponencia ${ }^{4}$ señalaba en su art. 86.2 que "en cada periodo ordinario de sesiones del Congreso se celebrará al menos un debate sobre la orientación de la política general del Gobierno". De tal modo que la Ponencia constitucional entendió que la articulación de las relaciones entre las Cortes Generales y el Gobierno se articularía, entre otros mecanismos, a través de los debates de política general que en cada periodo de sesiones se

3 https://app.congreso.es/consti/constitucion/elaboracion/index.htm

4 Como consecuencia del carácter reservado de las reuniones de la Ponencia no existe acta oficial de las mismas.

La Revista de las Cortes Generales publicó en su número 2 de 1984 la minutas y actas. En las mismas, la única referencia a esta cuestión, en donde aparece como artículo 87, es la siguiente:

“Artículo 87. 1. El Gobierno responde políticamente de su gestión de modo colectivo, ante el Congreso de los Diputados.

2. A1 menos en cada sesión ordinaria del Congreso se celebraran dos debates sobre la orientación de la política general del Gobierno.

3. El Gobierno puede formular declaraciones de política general ante ambas Cámaras.”

"Las actas de la ponencia constitucional”, Revista de las cortes Generales, núm. 2, 1984, pág. 298.

5 Anteproyecto de Constitución Española

Título IV De las Cortes Generales,

Capítulo Tercero De las relaciones entre el Gobierno y las Cortes Generales

"Artículo 86

1.- El Gobierno responde solidariamente de su gestión política ante el Congreso de los Diputados.

2.- En cada periodo ordinario de sesiones del Congreso se celebrará al menos un debate sobre la orientación de la política general del Gobierno.

3.- El Gobierno puede formular declaraciones de política general ante ambas Cámaras.”

Boletín Oficial de las Cortes, núm. 44, de 5 de enero de 1978, página 683. 
desarrollarían para que el gobierno, de un lado, rindiese cuentas de su gestión, y de otro, presentase sus futuras líneas de actuación

El acuerdo generalizado sobre la constitucionalización de esta institución parlamentaria lo expresa el hecho de que ninguno de los Grupos parlamentarios: Alianza Popular, Comunista, Minoría catalana, Socialistas del Congreso o Unión de Centro Democrático, presentó ningún voto particular frente al texto de la Ponencia que hiciera mención al art. 86 del Anteproyecto ${ }^{6}$.

\section{LA TRAMITACIÓN EN EL CONGRESO DE LOS DIPUTADOS}

En cuanto al trámite de presentación de enmiendas en el Congreso de los Diputados a dicho Anteproyecto hemos de indicar que una de ellas tiene por objeto al precepto objeto de estudio. En este sentido, en el índice de enmiendas publicado por el Congreso de los Diputados ${ }^{7}$ aparece una referencia al art. 86.2, a saber, la enmienda $\mathrm{n}^{0} 2$ presentada por el Sr. Carro Martínez, en representación de Alianza Popular. En este sentido, la citada enmienda incluye al art. 86 indicando que "El número 2 debe suprimirse, pues el debate político general debe hacerse con ocasión de los Presupuestos.”.

Se alinea esta enmienda con la concepción del parlamentarismo clásico que identifica a los debates sobre política general con el debate sobre los Presupuestos Generales del Estado, entendiendo que éste es el único contexto en el que dichos debates deben realizarse. Todo ello derivado de la consideración que merece el Parlamento y su relación con el Gobierno en el seno de primigenio Estado constitucional de corte liberal y el entendimiento que en el mismo se realiza de la división de poderes. Obviando la naturaleza de la relación entre Legislativo y Ejecutivo dentro del estado social y en el marco de un sistema parlamentario de Gobierno.

A este respecto, ha de hacerse referencia, de forma inevitable, al Informe de la Ponencia ${ }^{8}$, del cual resulta que el Capítulo Tercero, De las relaciones entre el Gobierno y las Cortes Generales, del Título IV De las Cortes Generales, pasa a ser el Título V del texto constitucional, correspondiéndose el anterior art. 86 con el 100. Sobre el reconocimiento constitucional del debate sobre los debates de política general, el informe mantiene el texto del anteproyecto no aceptando la enmienda del Sr. Carro Martínez ${ }^{9}$ al plantear una

6 Boletín Oficial de las Cortes, núm. 44, de 5 de enero de 1978, páginas 698 a 779.

7 Constitución Española, Trabajos Parlamentarios, Publicaciones de las Cortes Generales, Madrid, 1989, Tomo I, p. 95.

8 Boletín Oficial de las Cortes, num. 82, de 17 de abril de 1978, páginas 1519 y ss.

9 CONGRESO DE LOS DIPUTADOS, Anteproyecto de Constitución: Informe de la Ponencia

"TITULO V

De las relaciones entre el Gobierno y las Cortes Generales

La enmienda $n^{\circ} 2$ del Sr. Carro Martínez plantea una reconsideración general de todo el Capítulo Tercero, que no es aceptada por la Ponencia, al seguir la redacción de la misma un criterio diferente a la propuesta por la enmienda. Artículo 86.

Corresponde ahora al artículo 100.

Apartado 1.

La Ponencia mantiene, por mayoría, con la oposición de los representantes de los Grupos Socialista y Comunista, el texto del anteproyecto y no acepta, en consecuencia, por idéntica mayoría, las enmiendas número 284 del Grupo Socialista de Cataluña, y n.” 418 del Grupo Socialista del Congreso. La redacción es la siguiente:

1. El Gobierno responde solidariamente de su gestión política ante el Congreso de los Diputados.

Apartado 2. 
reconsideración general del todo el Capítulo Tercero, que no es aceptada por la Ponencia, al seguir la redacción de dicha Ponencia un criterio diferente a la propuesta de la enmienda. De tal modo, que así aparece recogido en el anexo del Informe de la Ponencia en el que figura la redacción del texto definitivo fruto de la consideración de las enmiendas presentadas $^{10}$.

Del dictamen de la Comisión de Asuntos Constitucionales y Libertades Públicas sobre el Anteproyecto de Constitución ${ }^{11}$ ha de destacarse que el Título IV, pasa a denominarse Título V y el art. 100 pasa a ser el 101, con la misma redacción dada por la Ponencia. Aunque el hecho más relevante es que dicho artículo no es objeto de ningún voto particular o enmienda tras este trámite como se deduce de la lectura de las propuestas de modificación planteadas ${ }^{12}$.

Así las cosas, el texto del Proyecto de Constitución, aprobado por el Pleno del Congreso de los Diputados el 21 de julio de 1978, incluía en su art. 101.2 $2^{13}$ la obligación de celebrar al menos un debate de política general en cada periodo ordinario de sesiones del Congreso, mientras que en el apartado $3^{\circ}$ se mantenía la posibilidad de que el Gobierno realizara declaraciones de política general ante cualquiera de las dos cámaras.

Por tanto, el Pleno del Congreso de los Diputados hizo suyo el planteamiento de la Ponencia y consagró como eje de las relaciones entre las Cortes Generales y el Gobierno el desarrollo de los debates de política general.

\section{LA TRAMITACIÓN EN EL SENADO}

En cuanto a la tramitación del Proyecto de Constitución en el Senado ${ }^{14}$ hemos de comenzar señalando que el art. 101.2 fue objeto de tres enmiendas, la n ${ }^{\circ} 226$ por D. Fidel Carazo

En cuanto a este apartado, la Ponencia mantiene, igualmente el texto del anteproyecto, no aceptando por las razones expuestas la enmienda n. 2 del Sr. Carro

Martínez. La redacción es la siguiente:

2. En cada período ordinario de sesiones el Congreso celebrará al menos un debate sobre la orientación de la política general del Gobierno.

Apartado 3.

La Ponencia acepta la enmienda n. 691 del Sr. López Rodó y redacta, en consonancia este apartado. La redacción es la siguiente:

3. El Gobierno puede formular declaraciones de política general ante una y otra Cámara”.

Boletín oficial de las Cortes, núm. 82, de 17 de abril de 1978, páginas 1571.

Constitución Española, Trabajos Parlamentarios, op. cit., Tomo I, p. 126.

10 Boletín Oficial de las Cortes, num. 82, de 17 de abril de 1978, página 1633.

11 Boletín Oficial de las Cortes, num. 121, de 1 de julio de 1978, página 2608.

12 Boletín Oficial de las Cortes, núm. 121, de 1 de julio de 1978, página 2623 a 2639.

13 TITULO V

De las relaciones entre el Gobierno y las Cortes Generales

Artículo 101.

1. El Gobierno responde solidariamente en su gestión política ante el Congreso de los Diputados.

2. En cada período ordinario de sesiones del Congreso se celebrará al menos un debate sobre la orientación de la política general del Gobierno.

3. El Gobierno puede formular declaraciones de política general ante una y otra Cámara.

Boletín Oficial de las Cortes, núm. 135, de 24 de julio de 1978, página 2962.

14 Constitución Española, Trabajos Parlamentarios, op. cit., Tomo III, pp. 2643 y 2644. 
Hernández, la nº 744 por la Unión de Centro Democrático, y la nº 798 por la Entesa Dels Catalans ${ }^{15}$.

El debate y votación de las enmiendas se produjo en el seno de la Comisión de la Constitución, en donde los apartados 1 y 2 del art. 101 permanecieron inalterados y sólo fue aprobada una enmienda relativa al apartado $3^{16}$. Este hecho queda reflejado en el

15 Las citadas enmiendas tenían el siguiente contenido:

a) La n 226 (Constitución Española, Trabajos Parlamentarios, op. cit., Tomo III, p. 2762) presentada por D. Fidel Carazo en representación del Grupo Mixto, propone quitar "del congreso se celebrará" y cambiarlo por "tendrá lugar ante las Cámaras reunidas conjuntamente".

b) Mientras que la enmienda $\mathrm{n}^{\mathrm{o}} 744$ (Constitución Española, Trabajos Parlamentarios, op. cit., Tomo III, p. 2985), cuyo primer firmante era la Unión de Centro Democrático lisa y llanamente proponía la supresión del art. 101.2, manteniendo los otros dos apartados del art. 101.

c) Finalmente, la n 798 (Constitución Española, Trabajos Parlamentarios, op. cit., Tomo III, p. 3004), presentada por la Entesa dels Catalans propone la siguiente redacción para el art. 101.2 "2. En cada periodo ordinario de sesiones de las Cortes Generales se celebrará al menos un debate en el Congreso sobre la orientación de la política general del Gobierno. Asimismo, se celebrará en el Senado, si esta Cámara lo solicita."

16 Es relevante citar el debate sobre las enmiendas al art. 101 para poner de manifiesto el acuerdo sobre la permanencia en el texto constitucional de los debates sobre política general:

"El señor PRESIDENTE: Entramos en la discusión del artículo 101. El señor Carazo tiene la palabra para defender su enmienda. (Pausa.) Se da por decaída.

La Agrupación Independiente tiene la palabra para defender su enmienda al apartado 1.

El señor OLLERO GÓMEZ: Queda retirada.

El señor PRESIDENTE: Entesa dels Catalans tiene la palabra para defender la enmienda 798 al apartado 2.

El señor BENET MORELL: Se retira.

El señor PRESIDENTE: Unión de. Centro Democrático tiene la palabra para defender la enmienda 744 al apartado 3.

El señor JIMÉNEZ BLANCO: Se retira.

El señor LÓPEZ HENARES: Perdón, la enmienda que retira UCD me gustaría presentarla como enmienda «in voce» mía.

El señor PRESIDENTE: Defiéndala el señor Senador, ya que el texto lo tenemos aquí.

El señor LÓPEZ HENARES: Esta enmienda se defiende por sus propios términos y, por lo tanto, quiero ahorrar tiempo a la Comisión.

El señor PRESIDENTE: Muchas gracias.

¿Turno en contra? (Pausa.) ¿Señores portavoces? (Pausa.)

Pasamos a votar, en primer lugar, los apartados 1 y 2 del artículo 101. ¿Se aprueban? (Asentimiento.) Quedan aprobados los apartados 1 y 2.

Pasamos al apartado 3. ¿Señores Senadores que voten a favor de la enmienda del señor López Henares?

Efectuada la votación, fue rechazada la enmienda por siete votos en contra y dos a favor, con 16 abstenciones.

El señor PRESIDENTE: ¿El señor López Henares mantiene su derecho de defenderla en el Pleno?

El señor LÓPEZ HENARES: No, señor Presidente.

El señor PRESIDENTE: Pasamos a votar el apartado 3 del artículo 101.

Efectuada la votación, fue aprobado por 24 votos a favor, con una abstención.

El señor PRESIDENTE: El señor De la Cierva va a dar lectura al artículo 101.

El señor VICEPRESIDENTE (De la Cierva y de Hoces): Dice así:

“Artículo 101.1. El Gobierno responde solidariamente en su gestión política ante el Congreso de los Diputados.

2. En cada período ordinario de sesiones de1 Congreso se celebrará al menos un debate sobre la orientación de la política general del Gobierno.

3. El Gobierno puede formular declaraciones de política general ante una y otra Cámara."”

Diario de Sesiones del Senado, núm. 50, 6 de septiembre de 1978, páginas 2375 y 2376. 
Dictamen de la Comisión de la Constitución ${ }^{17}$ en donde dicho precepto queda regulado como art. $107^{18}$. Así pues, el precepto que nos ocupa quedó redactado del siguiente modo:

"Artículo 107.

2. En cada período ordinario de sesiones de1 Congreso se celebrará al menos un debate sobre la orientación de la política general del Gobierno."

En cuanto a los votos particulare ${ }^{19}$ emitidos sobre dicho Dictamen ha de señalarse que sobre el citado precepto sólo se presentó un voto relativo a su apartado $3^{\circ}$ coincidente con la enmienda 744 anteriormente citada ${ }^{20}$.

El acuerdo alcanzado en la Comisión se manifestó en el debate en el Pleno del Senado $^{21}$ en donde el art. 107 fue aprobado sin ningún voto en contra. Así, en las modificaciones propuestas por el Pleno del Senado al texto del proyecto de Constitución aprobado por el Congreso de los Diputados no aparece ninguna referencia al precepto objeto de estudio al no sufrir éste ninguna alteración ${ }^{22}$.

Por lo tanto, el texto relativo a los debates de política general aprobado por la Ponencia fue aprobado y ratificado, de forma análoga y coincidente tanto por el Pleno del Congreso de los Diputados como por el Pleno del Senado.

\section{LA LABOR DE LA COMISIÓN MIXTA CONGRESO-SENADO}

Así las cosas, habiéndose modificado el texto final aprobado por el Congreso de los Diputados en el Senado se hacía necesario activar las previsiones que al respecto se habían establecido en la Ley para la Reforma Política ${ }^{23}$, procediéndose a la constitución de una

17 Diario de Sesiones del Senado, núm. 157, 6 de octubre de 1978, páginas 3415 a 3449.

18 Diario de Sesiones del Senado, núm. 157, 6 de octubre de 1978, página 3433.

19 Diario de Sesiones del Senado, núm. 157, 6 de octubre de 1978, páginas 3449 a 3527.

$20 \mathrm{Al}$ artículo 107, apartado 3.

Voto particular número 326 (enmienda número 744, de don José Luis López Henares. "El Gobierno puede formular declaraciones de política general ante una u otra Cámara o ante las dos Cámaras conjuntamente."

Diario de Sesiones del Senado, núm. 157, 6 de octubre de 1978, página 3491.

21 "El señor PRESIDENTE: Seguidamente ponemos a votación los artículos 107, 108, 109 y 110, que no tienen votos particulares, o algunos habían sido retirados por sus proponentes. Vamos a votar, por tanto, conjuntamente los cuatro artículos, del 107 al 110, ambos inclusive.

Efectuada la votación, quedaron aprobados por 125 votos."

Diario de Sesiones del Senado, núm. 63, 30 de septiembre de 1978, página 3160.

22 Diario de Sesiones del Senado, núm. 63, 30 de septiembre de 1978, páginas 3559 a 3577.

23 LEY PARA LA REFORMA POLÍTICA:

"Artículo tercero

Uno. La iniciativa de reforma constitucional corresponderá:

a) Al Gobierno.

b) Al Congreso de los Diputados.

Dos. Cualquier reforma constitucional requerirá la aprobación por la mayoría absoluta de los miembros del Congreso y del Senado. El Senado deliberará sobre el texto previamente aprobado por el Congreso, y si éste no fuera aceptado en sus términos, las discrepancias se someterán a una Comisión Mixta, bajo la presidencia de quien ostentara la de las Cortes y de la que formarán parte los Presidentes del Congreso y del Senado, cuatro Diputados y cuatro Senadores, elegidos por las respectivas Cámaras. Si esta Comisión no llegara a un acuerdo o los términos del mismo no merecieran la aprobación de una y otra Cámara, la decisión se adoptará por mayoría absoluta de los componentes de las Cortes en reunión conjunta de ambas Cámaras.

Tres. El Rey, antes de sancionar una Ley de Reforma Constitucional, deberá someter el Proyecto a referéndum de la Nación.” 
Comisión mixta ${ }^{24}$ con igual número de miembros de ambas Cámaras. Tal es así que el Senado, en la última sesión dedicada al debate y aprobación del Proyecto de Constitución finalizó la misma procediendo a la elección de los senadores, titulares y suplentes, que formarían parte de la misma ${ }^{25}$.

Hemos de iniciar este análisis indicando que vista la tramitación parlamentaria que tanto en el Congreso de los Diputados como en el Senado había tenido el precepto objeto de estudio nada hacía esperar que sufriese ninguna modificación habiendo sido aprobado por el Congreso y ratificado por el Senado. Ahora bien, de forma inexplicable el Dictamen de la Comisión Mixta Congreso-Senado sobre el proyecto de Constitución ${ }^{26}$, eliminó los apartados segundo y tercero del art. 107, convertido de forma definitiva en el art. 108, suprimiendo la referencia constitucional a los debates de política general y a la posibilidad de realizar declaraciones de política general por parte del Gobierno en cualquiera de las dos Cámaras ${ }^{27}$.

La primera conclusión a la que podemos llegar es clara y meridiana, no parece muy coherente que un precepto que es introducido por la Ponencia, que es aprobado por las comisiones y los Plenos de Congreso y Senado, sea suprimido por la Comisión Mixta. Asimismo, ha de señalarse la ausencia de actas de las sesiones de dicha Comisión que reflejen el método de trabajo y los criterios de actuación de la misma. En cualquier caso, parece obvio que dicha Comisión debería haber actuado articulando solamente aquellas materias en las que existieran discrepancias, pero no aquellas otras en las que la voluntad de ambas Cámaras hubiese sido análoga y coincidente ${ }^{28}$.

Boletín Oficial del Estado, núm. 4, de 5 de enero de 1977, páginas 170 a 171.

24 La designación de los miembros de la Comisión Mixta se produjo del siguiente modo:

CONGRESO DE LOS DIPUTADOS

"El Pleno del Congreso de los Diputados, en su sesión del día de hoy, ha elegido para formar parte de la Comisión Mixta que, de acuerdo con lo previsto en el artículo 3." de la Ley para la Reforma Política, debe dictaminar sobre las discrepancias entre el Congreso de los Diputados y el Senado acerca del texto de la Constitución, a los siguientes señores Diputados:

- Don Alfonso Guerra González.

- Don José Pedro Pérez-Llorca Rodrigo.

- Don Miguel Roca Junyent.

- Don Jorge Solé Tura."

Boletín Oficial de las Cortes, núm. 164, de 18 de octubre de 1978, página 608.

SENADO

"El señor VILLAR ARREGUII: En virtud de un acuerdo entre los portavoces de todos los Grupos Parlamentarios, se formula la siguiente propuesta de miembros de la Comisión Mixta: en concepto de titulares:

- don Femando Abril Martorell,

- don Antonio Jiménez Blanco,

- don Francisco Ramos Fernández-Torrecilla y

- don José Vida Soria.

Y en concepto de suplentes, como previene el Reglamento de esta Cámara, por este orden y con referencia a cada uno de los antes citados por su orden también: don David Pérez Puga, don Cecilio Valverde Mazuelas, don Josep Benet Morell y don Lorenzo Martín-Retortillo Baquer."

Diario de Sesiones del Senado, núm. 67, 5 de octubre de 1978, páginas 3365 y ss.

25 Véase el Diario de Sesiones del Senado, núm. 67, 5 de octubre de 1978, páginas 3365 y ss.

26 Boletín Oficial de las Cortes, núm. 170, de 28 de octubre de 1978, página 3701 a 3736.

27 Boletín Oficial de las Cortes, núm. 170, de 28 de octubre de 1978, página 3720.

28 "No deja de ser paradójico que la pretensión de suprimir estos dos apartados, expresada a través de la enmienda promovida por el Diputado de Alianza Popular Carro Martínez (I, pág. 126), fracasara y fuera rechazada en el Informe de la Ponencia creada en el seno de la Comisión de Asuntos Constitucionales y Libertades Públicas del Congreso de los Diputados (BOC núm. 82, de 17 de abril de 1978) y que, finalmente, habiendo superado estos dos 
Llegados a este punto y constatada la actuación de la Comisión, se hace necesario preguntarse cuál era, cuál debía ser la naturaleza de la actividad de la misma, si su función ${ }^{29}$ era la de presentar un único texto a Congreso y Senado y garantizar su aprobación.

A este respecto, cabrían, en principio, tres opciones, entenderla como un órgano técnico, como un órgano político o como un órgano técnico-político. Si se considera a la Comisión como un órgano que debe actuar sólo bajo criterios estrictamente jurídicos, ésta debería estar orientada, de forma exclusiva, a propiciar la consecución de la voluntad parlamentaria y del acuerdo entre ambas Cámaras a través de la presentación de un texto de consenso allí donde no hubiese acuerdo entre las mismas intentando armonizar las disposiciones discrepantes, respetando la naturaleza sistémica del texto constitucional. Si atendiésemos a su naturaleza estrictamente política, la Comisión estaría habilitada para desempeñar su labor buscando el acuerdo político que fructificase en el posterior apoyo al texto, más allá de consideraciones técnicas. Finalmente, podríamos configurarla como un órgano técnico político, que conjugase tanto los necesarios elementos de técnica jurídica como los derivados de la necesidad de alcanzar el consenso político que debería arropar al texto constitucional resultante.

En cuanto a los caracteres de la comisión, hemos de indicar que de la conformación de la Comisión Mixta Congreso-Senado, siguiendo los criterios de VIRGA ${ }^{30}$ se derivaba una Comisión paritaria, obligatoria, temporal y unitaria. Paritaria, pues se prevé que cada cámara estará representada por su presidente y por cuatro miembros de la misma. Obligatoria, ya que la Ley para la reforma Política prevé ineludiblemente su constitución si se producen discrepancias entre el texto aprobado por el Congreso y el aprobado por el Senado. Temporal, pues su existencia se ve vinculada a la elaboración de un texto alternativo y definitivo. Finalmente, es una comisión unitaria en la que confluye el carácter representativo de las dos Cámaras.

De la literalidad de la Ley para la Reforma Política parece deducirse que la naturaleza de la Comisión Mixta sería de carácter técnico, limitada a la superación de las discrepancias mediante la elaboración de un texto alternativo, cuando fuese necesario, asumible por ambas Cámaras.

En este sentido, y partiendo de esta tesis parece claro que en el seno de la Comisión sólo deberían haberse debatido aquellos preceptos, títulos o contenidos que hubiesen sido configurados de forma dispar por cada una de las Cámaras.

Este planteamiento rechazaría el hecho de que la Comisión Mixta invadiese las competencias propias y específicas de las Cámaras, al revisar, modificar o alterar lo que se hubiese aprobado en ambos Plenos en idéntico sentido y literalidad.

Lo contrario supondría el traslado de la competencia de las Cámaras a la Comisión, constituida en auténtica Cámara de representación general. A ello debe añadirse la

apartados todos los avatares a los que enseguida haremos referencia, fueran suprimidos sin ninguna justificación por la Comisión Mixta Congreso-Senado."

MATÍA PORTILLA, F.J.: "Artículo 108. El Gobierno responde solidariamente en su gestión política ante el Congreso de los Diputados", Comentarios a la Constitución Española, Drs. Miguel Rodríguez-Piñero y Bravo Ferrer, María Emilia Casas Baamonde 2018, Madrid, Fundación Wolters Kluwer, Boletín Oficial del Estado, Tribunal Constitucional y Ministerio de Justicia, pág. 569.

29 GARCÍA HERRERA, M. A.: La comisión mixta Congreso-Senado, Revista de estudios políticos, № 4, 1978, págs. 67-96

30 VIRGA, P.: “Le Commissioni Miste”, Riv. Trim. Di Dir. Pubb., 1953, págs. 514-15. 
deficiente representatividad de la misma, contraviniendo los mínimos estándares sobre pluralidad de los órganos parlamentarios ${ }^{31}$, que atendiendo a la jurisprudencia de nuestro Tribunal Constitucional ha de asegurar el pluralismo democrático y la proporcionalidad representativa de los mismos. La inclusión de los presidentes de las dos Cámaras junto el de las Cortes Generales suponía un reforzamiento de los grupos que conformaban la mayoría parlamentaria. Por otro lado, la asignación de sólo cuatro miembros a Congreso y Senado cercenaba la posible representación de numerosos grupos de cada una de las Cámaras. Más allá de la disfuncionalidad de esa preeminencia de los grupos gubernamentales tal composición era una merma de su legitimidad.

Supondría, en sí mismo, la creación de un centro de poder carente de la necesaria previsión y garantías en cuanto a su actuación

De tal modo que no podría sino concluirse que la Comisión Mixta no habría sido configurada como un poder de revisión sino como una instancia que propiciase la coordinación de los criterios utilizados por cada una de las Cámaras.

Siguiendo esta argumentación, la Comisión sólo debería haber trabajado sobre los puntos sobre los que se hubiese manifestado un desacuerdo, intentando respetar el espíritu de texto aprobado por las Cámaras con la finalidad de producir un texto alternativo fiel al principio de coherencia con el conjunto normativo e inspirándose en los principios que propiciaron el previo debate parlamentario.

Ahora bien, en relación a la cuestión que nos ocupa, precisamente, la unanimidad mostrada en las diversas instancias por las que discurrió la tramitación del precepto imposibilita que se puedan analizar los distintos argumentos que se hubiesen podido contraponer y expresar en el debate político y parlamentario, por lo que tampoco se puede determinar ninguna causa, fundamento o argumentación sobre la que poder basar la definitiva supresión del mismo en el seno de la Comisión.

Otro elemento de reflexión es el relativo a la cualidad de los miembros de las Cámaras designados para integrar la Comisión Mixta, atendiendo a la naturaleza representativa de su mandato y a la prohibición de mandato imperativo, que habrá de conjugar con su condición de miembro de una de las Cámaras que actúa en representación de las misma y de un texto que él ha coadyuvado a conformar y de la diputado o senador de una determinada formación política que ha defendido unas determinadas tesis durante el proceso constituyente. Se entiende que la posición de los miembros de la Comisión debería distanciarse tanto del férreo mandato como de la arbitrariedad y subjetividad, desarrollándose en el terreno de los límites políticos e institucionales de cada uno de ellos.

\section{CONCLUSIONES}

Dicho todo lo anterior, la lógica más elemental indicaría que no deberían haber sido modificados aquellos elementos en los que hubiese consenso entre ambas Cámaras, pues lo contrario deslegitimaría la anterior labor parlamentaria caracterizada, sin lugar a dudas, por ser más participativa y plural que una Comisión de once miembros, cuya única competencia legalmente establecida era determinar un texto de consenso donde hubiese

31 Entre otras se pueden estudiar la STC 199/2016, de 28 de noviembre, y la STC 141/1990, de 20 de septiembre. 
discrepancia. Lo contrario sería admitir que el texto, elaborado en su inicio por la Ponencia, y modificado y conformado tras un año de incesante trabajo parlamentario por el Congreso de los Diputados y el Senado, sería determinado en todos sus aspectos, por una "segunda" Ponencia.

De tal modo que, si se modificó por iniciativa propia evidenciaría una clara extralimitación de la Comisión Mixta que no se limitó a concordar o a mejorar la redacción. Mientras que si se modificó de forma subrepticia ello supondría un grave quebrantamiento del principio de buena fe, inspiración del largo procedimiento utilizado. En cualquier caso, entendemos que en lugar de haberse adoptado este acuerdo sobre su supresión en el seno de la Comisión Mixta lo aconsejable habría sido que el rechazo al mismo se hubiere puesto de manifiesto con anterioridad por cualquier fuerza política en cualquiera de las dos Cámaras. Más allá de la decisión concreta que se hubiese adoptado, o la instancia donde se hubiese producido la misma, creemos que lo trascendente habría sido, como mínimo, la constatación de una discrepancia o disenso de la suficiente relevancia durante su tramitación parlamentaria que justificase la posterior intervención de la comisión.

El procedimiento constituyente bicameral abocó al necesario acuerdo entre Congreso y Senado. En este momento adquirió una importancia decisiva el papel de la Comisión Mixta como articuladora del texto definitivo que sería sometido a ambas Cámaras y al pueblo, sin posibilidad de votos particulares y enmiendas, se antoja, vistos los resultado concretos, determinante, a la vez que oscuro.

El propio Hernández Gil, defendiendo el Dictamen de la Comisión ante el Pleno del Senado hacía referencia a la multiplicidad de criterios usados por la misma: criterios de coherencia, o de integridad, o de integración, o de complementariedad ${ }^{32}$. Estas pautas en su ambigüedad, junto al examen del texto resultante, ponen de manifiesto que la Comisión Mixta, se extralimitó en las competencias que le había atribuido la Ley para la Reforma Política. Puede que ese exceso pudiera merecer una valoración, política o técnica positiva; pero jurídicamente, es de evidente irregularidad al contravenir las previsiones de la Ley para la Reforma Política.

32 "Puedo decir que con sumo honor presento, defiendo y someto a la consideración y al voto de Vuestras Señorías el dictamen sobre el proyecto de Constitución emitido por la Comisión Mixta. En conjunto no se trata de un proyecto nuevo y distinto, por el limitado alcance de las diferencias entre el Congreso y el Senado y por la naturaleza de la labor realizada por la Comisión Mixta. Podría afirmarse que, habiendo cambios en las palabras y en las expresiones normativas, la estructura de la Constitución subsiste plenamente después de la intervención de la Comisión Mixta. ¿Qué ha hecho y cómo lo ha hecho la Comisión Mixta? La Comisión Mixta ha comprobado, ante todo, la predominante conformidad entre los textos procedentes del Congreso de los Diputados y del Senado. En caso de discrepancia ha optado por un texto o por otro, y en determinadas ocasiones ha obtenido un texto distinto en los matices, bien por vía de refundición, bien por vía de coherencia, o de integridad, o de integración, o de complementariedad. Esos han sido los criterios con los que ha operado la Comisión Mixta: teniendo en consideración las discrepancias, pero al mismo tiempo tomando en cuenta que las normas no son compartimientos estancos, sino que constituyen elementos integrados y mutuamente vinculados y dependientes en el seno de un ordenamiento jurídico y, en concreto, dentro de un contexto constitucional,

¿Cómo ha procedido la Comisión Mixta?

Pues yo afirmaría que sólo ha habido en el seno de la Comisión Mixta una posición radical, pero una posición radical compartida por todos, y es la de hacer todo lo posible, extremar el diálogo, hasta conseguir un acuerdo, hasta lograr una unanimidad de la que nos sentimos, al mismo tiempo que satisfechos, solidariamente responsables, sin ninguna diferencia, todos y cada uno de los miembros de la Comisión Mixta.”Diario de Sesiones del Senado, 31 octubre 1978, pág. 3395 
Un documento final que, como se puede apreciar, no tenía por qué respetar lo acordado por Congreso y Senado y que sería sometido, tras dos años de trabajo, a su elaboración y aprobación definitiva en el plazo inferior a un mes.

Con dicha redacción final el texto fue aprobado en sesión plenaria por el Congreso de los Diputados y por el Senado y sometido a referéndum de los electores, no quedando constitucionalizados, finalmente, los debates sobre política general. Una supresión fruto de una transacción o acuerdo de carácter político, pues carecemos de criterios para entender que fuese el resultado de un análisis técnico jurídico. Se anulaban así las previsiones realizadas que ponían de manifiesto la naturaleza constitucional de nuestro objeto de estudio y lo conformaban como un instrumento de control del Parlamento, un mecanismo ordinario de rendición de cuentas del gobierno ante el Parlamento, indisponible para el Gobierno. 